\title{
Association of Fibrinogen with Parkinson Disease in Elderly Japanese-American Men: A Prospective Study
}

\author{
K.T. Wong ${ }^{a} \quad$ J.S. Grove ${ }^{a} \quad$ A. Grandinetti ${ }^{a} \quad$ J.D. Curb ${ }^{\text {b, d, e }}$ M. Yee ${ }^{b} \quad$ P. Blanchette ${ }^{b}$ \\ G.W. Ross ${ }^{\text {b-f }}$ B.I. Rodriguez ${ }^{\text {b, }}$, e \\ Departments of a Public Health Sciences, ${ }^{b}$ Geriatric Medicine, and ${ }^{c}$ Medicine, John A. Burns School of Medicine, \\ University of Hawaii, dPacific Health Research Institute, ${ }^{e}$ Honolulu Heart Program and Honolulu-Asia Aging Study, \\ Kuakini Medical Center, and ${ }^{f}$ Veterans Affairs Pacific Islands Health Care System, Honolulu, Hawaii, USA
}

\section{Key Words}

Fibrinogen $\cdot$ Parkinson disease $\cdot$ Asian-Americans

\begin{abstract}
Background: The purpose of this prospective study was to examine whether fibrinogen level is associated with Parkinson disease (PD) for both prevalent and incident cases. Methods: The Honolulu Asia-Aging Study is a longitudinal study of Japanese-American men based on the Honolulu Heart Study birth cohort. The original cohort consisted of 8,006 participants with selective service records who were living on the island of Oahu, Hawaii, in 1965. For this analysis, baseline was defined as the 1991-1993 examination ( $n=3,845)$ when men were aged 71-93 years old. Multivariate logistic regression and Cox proportional hazards models were used, adjusting for potential confounders. Results: We identified 61 prevalent cases and 61 incident cases of PD during the follow-up. High fibrinogen level (presence in the top quintile) was associated with higher frequency of PD for both prevalent $(\mathrm{OR}=2.07,95 \% \mathrm{Cl}=1.10-3.88, \mathrm{p}=0.024)$ and incident cases $(\mathrm{HR}=3.05,95 \% \mathrm{Cl}=1.34-6.97, \mathrm{p}=0.008)$ among
\end{abstract}

men aged 76-93 years, after adjusting for age, smoking, and low-density lipoprotein cholesterol. Conclusions: These results suggest high fibrinogen level is associated with increased risk of PD among men over 75 years.

Copyright $\odot 2009$ S. Karger AG, Basel

\section{Introduction}

Parkinson disease (PD) is one of the most common neurodegenerative diseases affecting the elderly, with rates increasing dramatically with age [1]. It is a motor disorder primarily characterized by dopaminergic neuron loss and intracellular inclusions (known as Lewy bodies) in the substantia nigra [1-6]. Prevalence ranges from 0.7 to $3 \%$ among persons aged 65 years and older [7-11] and is higher in men than in women $[8,9,12]$.

Researchers have suggested that inflammation may play a role in the neurodegenerative processes leading to PD. Previous studies have found an increased level of inflammatory mediators in the striatum, a large amount of activated microglia, along with the depletion of dopami-

\section{KARGER}

๑ 2009 S. Karger AG, Basel

Fax +41 613061234 E-Mail karger@karger.ch www.karger.com
G. Webster Ross, MD

Pacific Health Research Institute

700 Bishop St., Suite 900

Honolulu, HI 96813 (USA)

Tel. +1 808524 4411, Fax +1 808524 5559, E-Mail wross@phrihawaii.org 
nergic neurons and the presence of characteristic Lewy bodies in the substantia nigra of PD patients [4, 5, 13-15]. Plasma fibrinogen, an acute-phase protein found in the blood, is a sensitive marker of systemic inflammation [2, 16]. The Health Professionals Follow-up Study $(\mathrm{n}=249)$ was the first to prospectively investigate the relationship of peripheral inflammatory biomarkers and PD. Although fibrinogen was not found to be associated with PD risk, authors noted that the sample size was small [2].

Finding a significant biomarker of inflammation could be an important tool for predicting and preventing future PD risk. Therefore, the objective of this study was to examine whether fibrinogen level is associated with the frequency of $\mathrm{PD}$ in prevalent and incident cases in a population-based cohort of Japanese-American men.

\section{Methods}

\section{Study Population}

The Honolulu Heart Program is a long-term prospective study of cardiovascular disease among Japanese-American men. With the establishment of the Honolulu Asia-Aging Study in 1991, the focus of the Honolulu Heart Program shifted to include neurodegenerative disease research.

From a target population of 11,148 men with selective service records, born in 1900-1919 and living on the island of Oahu, Hawaii, in 1965, 8,006 agreed to participate. There has been ongoing surveillance of the subjects' health status. Follow-up has been exceptionally complete, due partly to the very low emigration rate.

Out of 4,678 eligible living participants from the original cohort of 8,006, 3,741 agreed to participate in the 1991-1993 cohort examination. Further details of the selection process have been previously published $[17,18]$. The study protocol was approved by the Kuakini Medical Center institutional review committee, and informed consent from all participants was obtained.

\section{Data Collection}

Blood was drawn from the participants to determine plasma fibrinogen levels at the 1991-1993 cohort examination. The samples were sent to the Laboratory for Clinical Biochemistry Research, University of Vermont, Colchester. Levels were determined on a BBL fibrometer (Becton Dickinson) and defined as the rate of clot formation by a semiautomated modification of the Clauss method. Calibration and quality control data details have been described elsewhere [19].
PD case finding and diagnosis began during the 1991-1993 examination and have continued through subsequent examinations (1994-1996, 1997-1999, and 1999-2001). A structured interview was conducted with all subjects about previous diagnosis of PD and use of PD medications. Further screening was done by a trained technician for recognition of clinical symptoms of parkinsonism (e.g. gait disturbance, tremor, and bradykinesia). During the 1999 examination, 9 questions related to parkinsonism were also administered by the technician. These questions have been validated in a case-control population, where they were found to have a sensitivity of $89 \%$ and a specificity of $88 \%$ [20]. Participants with a history of parkinsonism, clinical signs of parkinsonism, or (for the 1999 exam) 4 or more positive responses on the 9 screening questions were referred to a study neurologist. The study neurologists, using a standardized history and examination, diagnosed participants with PD according to published criteria which required the subjects to have: (1) parkinsonism (e.g. bradykinesia or resting tremor combined with rigidity or postural reflex impairment); (2) a progressive disorder; (3) any 2 of the following: a marked response to levodopa, asymmetry of signs, asymmetry at onset, or initial onset tremor; (4) absence of any etiology known to cause similar features. Parkinsonism cases related to progressive supranuclear palsy, multiple system atrophy, cerebrovascular disease, druginduced parkinsonism, post-encephalitic parkinsonism, or post-traumatic parkinsonism were not included among the PD cases [21].

\section{Statistical Analysis}

Men were followed through 2000 (10 years of follow-up) for the development of PD. As an operational definition of high fibrinogen, we used the upper $20 \%$ of values.

Multivariate logistic regression models were used for the prevalent analysis and Cox proportional hazards models were used for the longitudinal analysis. Presence of PD was the dependent variable and presence in the top quintile of fibrinogen was the primary independent variable. Odds ratios (ORs) and hazard ratios (HRs) were reported, with their corresponding p values. Age, smoking at baseline, and low-density lipoprotein cholesterol (LDL) assessed during the 1991-1993 examination were covariates in the models. Analyses were performed separately for 2 age groups ( $\leq 75$ and $>75$ years).

\section{Results}

Fibrinogen levels are reported in table 1 . The values ranged from 0.92 to $8.93 \mathrm{~g} / 1($ mean $=3.07 \mathrm{~g} / \mathrm{l}$, median $=$ $2.98 \mathrm{~g} / \mathrm{l})$.
Table 1. Baseline plasma fibrinogen levels (g/l) by quintile

\begin{tabular}{lllllll}
\hline & 1st & 2nd & 3rd & 4th & 5th & Total \\
\hline Range & $0.92-2.56$ & $2.57-2.83$ & $2.84-3.12$ & $3.13-3.50$ & $3.51-8.93$ & $0.92-8.93$ \\
Mean (SD) & $2.31(0.21)$ & $2.70(0.08)$ & $2.97(0.08)$ & $3.29(0.12)$ & $4.02(0.54)$ & $3.07(0.64)$ \\
\hline
\end{tabular}


Fibrinogen was chosen as the biomarker for inflammation because data on white blood cell count and C-reactive protein levels were only available in a subset of the participants. Age, smoking at baseline, and LDL were significant covariates and used in the models. Potential confounders that were not significant and not included in our final models were history of stroke, baseline physical activity, smoking at the 1991-1993 examination, plasma homocysteine level, non-steroidal anti-inflammatory drug use, and acetylsalicylic acid medication use at the 1991-1993 examination (table 2).

At the 1991-1993 examination, 61 prevalent cases of PD were identified. Among the prevalent cases, 13 participants were in the baseline age group (71-75 years) and 48 were aged 76-93 years. During the subsequent examinations, an additional 61 incident cases were identified. Of these cases, 34 participants were in the baseline age group (71-75 years) and 27 were aged 76-93 years (table 3 ).

The frequency of $\mathrm{PD}$ was elevated among the older men in the highest quintile of fibrinogen compared to men with a lower fibrinogen level (table 4). For prevalent cases, the OR was 2.07 ( $\mathrm{p}=0.024)$, and for incident cases the HR was $3.05(\mathrm{p}=0.008)$. The frequency of PD was not associated with high fibrinogen level among the younger men. The HR differed significantly between the 2 age groups when tested in 2 different ways. Using all participants, the results showed: (1) with a dummy variable for age category, the cross product of high fibrinogen with the dummy variable was significant ( $\mathrm{p}<0.03)$; (2) when treating age at baseline as a continuous variable, the cross product of age with high fibrinogen was highly significant $(p=0.0056)$. If fibrinogen level is treated linearly and pooled across all ages, the main effect of fibrinogen was not significant $(\mathrm{p}=0.36)$, but the interaction with age was significant $(\mathrm{p}=0.038)$.

Table 2. Potential confounders for development of PD

\begin{tabular}{lll}
\hline & $\begin{array}{l}\text { Prevalent } \\
\text { p value }\end{array}$ & $\begin{array}{l}\text { Incident } \\
\text { p value }\end{array}$ \\
\hline Age & 0.020 & 0.830 \\
History of stroke & 0.082 & 0.323 \\
Acetylsalicylic acid use & 0.594 & 0.347 \\
Non-steroidal anti-inflammatory drug use & 0.911 & 0.907 \\
Plasma homocysteine level & 0.778 & 0.970 \\
Baseline physical activity & 0.266 & 0.609 \\
LDL level & 0.045 & 0.087 \\
Smoking at baseline & 0.009 & 0.432 \\
Smoking at the 1991-1993 examination & 0.230 & 0.401 \\
\hline
\end{tabular}

Table 3. Numbers of prevalent and incident PD cases by quintile of fibrinogen

\begin{tabular}{lccccrr}
\hline & 1st & 2nd & 3rd & 4th & 5th & Total \\
\hline Prevalent PD cases & $15(24.6)$ & $14(23.0)$ & $10(16.4)$ & $5(8.20)$ & $17(27.9)$ & 61 \\
Prevalent participants & 755 & 694 & 653 & 763 & 706 & 3,571 \\
Incident PD cases & $14(23.0)$ & $13(21.3)$ & $7(11.5)$ & $14(23.0)$ & $13(21.3)$ & 61 \\
Incident participants & 680 & 681 & 646 & 749 & 693 & 3,510 \\
\hline
\end{tabular}

Figures in parentheses are percentages.

Table 4. Adjusted OR and HR for top quintile fibrinogen and PD

\begin{tabular}{|c|c|c|c|c|c|c|}
\hline \multirow{2}{*}{$\begin{array}{l}\text { Age group } \\
\text { years }\end{array}$} & \multicolumn{3}{|c|}{ Unadjusted } & \multicolumn{3}{|l|}{ Adjusted } \\
\hline & OR/HR & $95 \%$ CI & $\mathrm{p}$ value & $\mathrm{OR} / \mathrm{HR}$ & $95 \%$ CI & $\mathrm{p}$ value \\
\hline 71-75 (prevalent cases) & 0.742 & $0.163-3.37$ & 0.699 & 0.771 & $0.168-3.54$ & 0.738 \\
\hline 71-75 (incident cases) & 0.679 & $0.239-1.93$ & 0.468 & 0.702 & $0.245-2.01$ & 0.510 \\
\hline 76-93 (prevalent cases) & 1.76 & $0.948-3.27$ & 0.074 & 2.07 & $1.10-3.88$ & 0.024 \\
\hline 76-93 (incident cases) & 2.56 & $1.15-5.69$ & 0.022 & 3.05 & $1.34-6.97$ & 0.008 \\
\hline
\end{tabular}




\section{Discussion}

A high fibrinogen level was associated with higher prevalence and incidence of PD in participants aged 76 years and older. No effects were found in the younger age group, and the interaction between age and high fibrinogen was significant. These findings suggest that inflammatory mechanisms may play a greater role in older individuals.

There are several strengths to this study. This was a large population-based cohort study with all fibrinogen assays performed by one laboratory during a single interval. Follow-up was high for this cohort: of participants still alive, $80 \%$ of the men who attended the initial examination in 1965 attended the 1991-1993 examination some 26 years later. Risk factors were ascertained in detail by rigorous physical examinations performed with each participant at every follow-up [17]. Nine potential confounding variables were screened using multiple logistic regression models and Cox proportional hazards models. The covariates used in the final models included age (which is believed to influence the clinical progression of PD [1]), smoking (which has been shown in many studies to be protective [23-26]), and LDL (which has an inverse association with PD [22]). Of the 4 tests of association with high fibrinogen level ( 2 tests with incident cases and 2 with prevalent cases), 2 were significant. From the bi- nomial distribution, the probability of 2 or more tests being significant out of 4 is only 0.014 .

Limitations of this study include: unmeasured confounders, a small number of PD cases, particularly among men aged 71-75, and having only a single measurement of fibrinogen. In addition, men who had severe forms of PD may have been less likely to attend the ongoing examinations. Men were divided into 2 age groups (71-75 and 76-93). Although these divisions were arbitrary, the interaction of age with high fibrinogen was highly significant when age was treated as a continuous variable.

Our findings support the hypothesis of inflammation as a risk factor for PD, at least among men older than 75 , and provide a basis for further research using other biomarkers of inflammation to confirm the hypothesis.

\section{Acknowledgments}

This work was supported by National Parkinson Foundation; Hawaii Parkinson Disease Center of Excellence; the National Institutes of Health: National Institute on Aging (1 U01 AG19349 and 5 R01 AG017155); National Institute of Neurological Disorders and Stroke (5 R01 NS041265); Office of Research and Development, Medical Research Service Department of Veterans Affairs; and the United States Department of the Army (DAMD1798-1-8621). The information contained in this paper does not necessarily reflect the position or the policy of the government, and no official endorsement should be inferred.

\section{References}

1 Whitton PS: Inflammation as a causative factor in the aetiology of Parkinson's disease. Br J Pharmacol 2007;150:963-976.

-2 Chen H, O'Reilly EJO, Schwarzschild MA, Ascherio A: Peripheral inflammatory biomarkers and risk of Parkinson's disease. Am J Epidemiol 2008;167:90-95.

- 3 Chen H, Zhang SM, Hernan MA, Schwarzschild MA, Willett WC, Colditz GA, Speizer FE, Ascherio A: Nonsteroidal anti-inflammatory drugs and the risk of Parkinson disease. Arch Neurol 2003;60:1059-1064.

4 Hald A, Van Beek J, Lotharius J: Inflammation in Parkinson's disease: causative or epiphenomenal? Subcell Biochem 2007;42:249279.

5 Hald A, Lotharius J: Oxidative stress and inflammation in Parkinson's disease: is there a causal link? Exp Neurol 2005;193:279-290.

- 6 Ross GW, Petrovitch H, Abbott RD, Nelson J, Markesbery W, Davis D, Hardman J, Launer L, Masaki K, Tanner CM, White LR: Parkinsonian signs and substantia nigra neuron density in decendents elders without PD. Ann Neurol 2004;56:532-539.
7 Chen RC, Chang SF, Su CL, Chen TH, Yen MF, Wu HM, Chen ZY, Liou HH: Prevalence, incidence, and mortality of PD: a door-to-door survey in Ilan county, Taiwan. Neurology 2001;57:1679-1686.

-8 de Rijk MC, Breteler MMB, Graveland GA, Ott A, Grobbee DE, van der Meche FGA, Hofman A: Prevalence of Parkinson's disease in the elderly: the Rotterdam study. Neurology 1995;45:2143-2146.

-9 Mayeux R, Denaro J, Hemenegildo N, Marder K, Tang MX, Cote LJ, Stern Y: A population-based investigation of Parkinson's disease with and without dementia: relationship to age and gender. Arch Neurol 1992;49:492497.

10 Tanner CM, Goldman SM, Ross GW: Etiology of Parkinson's disease; in Jankovic JJ, Tolosa E (eds): Parkinson's Disease and Movement Disorders. Philadelphia, Lippincott, Williams, and Wilkins, 2002, pp 90 103.
11 Zhang ZX, Anderson DW, Huang JB, Li H, Hong X, Wei J, Yang EL, Maraganore DM: Prevalence of Parkinson's disease and related disorders in the elderly population of greater Beijing, China. Mov Disord 2003;18: 764-772.

12 Mayeux R, Marder K, Cote LJ, Denaro J, Hemenegildo N, Mejia H, Tang MX, Lantigua R, Wilder D, Gurland B, Hauser A: The frequency of idiopathic Parkinson's disease by age, ethnic group, and sex in northern Manhattan, 1988-1993. Am J Epidemiol 1995; 142:820-827.

13 Asanuma M, Miyazaki I, Ogawa N: Neuroprotective effects of nonsteroidal anti-inflammatory drugs on neurodegenerative diseases. Curr Pharm Design 2004;10:695700 .

14 Klegeris A, McGeer EG, McGeer PL: Therapeutic approaches to inflammation in neurodegenerative disease. Curr Opin Neurol 2007;20:351-357. 
-15 Tansey MG, McCoy MK, Frank-Cannon TC: Neuroinflammatory mechanisms in Parkinson's disease: potential environmental triggers, pathways, and targets for early therapeutic intervention. Exp Neurol 2007;208: $1-25$.

- 16 Yano K, Grove JS, Chen R, Rodriguez BL, Curb JD, Tracy RP: Plasma fibrinogen as a predictor of total and cause-specific mortality in elderly Japanese-American men. Arterioscler Thromb Vasc Biol 2001;21:10651070.

17 Kagan A: The Honolulu Heart Program: An Epidemiological Study of Coronary Heart Disease and Stroke. Harwood, Harwood Academic, 1996.

-18 Worth RM, Kagan A: Ascertainment of men of Japanese ancestry in Hawaii through World War II Selective Service registration. J Chronic Dis 1970;23:389-397.

-19 Sharp DS, Abbott RD, Burchfiel CM, Rodriguez BL, Tracy RP, Yano K, Curb JD: Plasma fibrinogen and coronary heart disease in elderly Japanese-American men. Arterioscl Throm Vas 1996;16:262-268.
20 Rocca WA, Maraganore DM, McDonnell SK, Schaid DJ: Validation of a telephone questionnaire for Parkinson's disease. J Clin Epidemiol 1998;51:517-523.

21 Ward CD, Gibb WR: Research diagnostic criteria for Parkinson's disease. Adv Neurol 1990;53:245-249.

22 Huang X, Chen H, Miller WC, Mailman RB, Woodard JL, Chen PC, Xiang D, Murrow RW, Wang YZ, Poole C: Lower low-density lipoprotein cholesterol levels are associated with Parkinson's disease. Movement Disord 2007;22:377-381.

23 Abbott RD, Ross GW, White LR, Sanderson WT, Burchfiel CM, Kashon M, Sharp DS, Masaki KH, Curb JD, Petrovitch H: Environmental, life-style, and physical precursors of clinical Parkinson's disease: recent findings from the Honolulu-Asia Aging Study. J Neurol 2003;250(suppl 3):III30III39.
24 Grandinetti A, Morens DM, Reed D, MacEachern D: Prospective study of cigarette smoking and the risk of developing idiopathic Parkinson's disease. Am J Epidemiol 1994;139:1129-1138.

25 Park HJ, Lee PH, Ahn YW, Choi YJ, Lee G, Lee DY, Chung ES, Jin BK: Neuroprotective effect of nicotine on dopaminergic neurons by anti-inflammatory action. Eur J Neurosci 2007;26:78-89.

26 Ritz B, Ascherio A, Checkoway H, Marder KS, Nelson LM, Rocca WA, Ross GW, Strickland D, Van Den Eeden SK, Gorell J: Pooled analysis of tobacco use and risk of Parkinson disease. Arch Neurol 2007;64:990-997.

-27 Markus HS, Tomkins AM, Stern GM: Increased prevalence of undernutrition in Parkinson's disease and its relationship to clinical disease parameters. J Neural Transm Park Dis Dement Sect 1993;5:117-125.

28 Rothman KJ: Epidemiology. New York, Oxford, 2002. 